\title{
Medidas de policía administrativa y régimen jurídico del servicio público: uso de las medidas correctivas en el Perú*
}

\author{
NOELIA CARRERAS SCHABAUER**
}

\begin{abstract}
CONTENIDO: INTRODUCCIÓN.- I. FORMAS DE INTERVENCIÓN DE LA ADMINISTRACIÓN: EL SERVICIO PÚBLICO Y LA ACTIVIDAD DE POLICÍA ADMINISTRATIVA.- I.1. ANÁLISIS ECONÓMICO: LA ORGANIZACIÓN DE LA PRODUCCIÓN Y EL PROBLEMA DEL PRINCIPAL-AGENTE APLICADO A LA PRESTACIÓN DE SERVICIOS PÚBLICOS.- II. POTESTAD SANCIONADORA DE LA ADMINISTRACIÓN Y EL PRINCIPIO DE TIPICIDAD: ALGUNOS PROBLEMAS.- II.1. SANCIÓN, MEDIDAS DE POLICÍA ADMINISTRATIVA Y MEDIDAS CORRECTIVAS: CONCEPTUALIZACIÓN.- III. DISEÑO NORMATIVO DE LAS MEDIDAS CORRECTIVAS.- III.1. JURISPRUDENCIA Y DECISIONES ADMINISTRATIVAS EN MATERIA DE MEDIDAS CORRECTIVAS.-IV. CONCLUSIONES Y RECOMENDACIONES.
\end{abstract}

\section{INTRODUCCIÓN}

El presente ensayo pretende ser una aproximación inicial a la noción de medidas de policía administrativa en el Derecho administrativo sancionador, al analizar la forma como esta institución jurídica ha sido regulada y la manera en que busca encontrar la lógica regulatoria detrás de las mismas. En primer lugar, se presentará un análisis de la actividad de policía administrativa y del régimen jurídico del servicio público conjuntamente con un análisis económico que sirva para definir sus premisas. En segundo lugar, se hará un repaso por la doctrina jurídica existente para delimitar el concepto de medida de policía administrativa. Seguidamente, se compararán los conceptos descritos con el régimen jurídico peruano de medidas correctivas. Finalmente, se propondrán algunos lineamientos a ser tomados en cuenta para la utilización de las medidas correctivas en sede administrativa, con especial incidencia en los organismos reguladores de los servicios públicos.

\section{FORMAS DE INTERVENCIÓN DE LA ADMINISTRACIÓN: EL SERVICIO PÚBLICO Y LA ACTIVIDAD DE POLICÍA ADMINISTRATIVA}

La naturaleza del servicio público ha sido ampliamente estudiada en la doctrina del Derecho Administrativo. Durante los últimos años, se ha decantado la noción de servicio público como un régimen jurídico que, entre otros, implica una fuerte intervención estatal respecto del actuar

\footnotetext{
* Trabajo ganador del tercer concurso de ensayos jurídicos organizado por la Revista Derecho PUCP.

** Egresada de la Facultad de Derecho de la PUCP en el semestre 2010-II.
} 
de los prestadores privados ${ }^{1}$. En otras palabras, nos encontramos ante agentes económicos sometidos de forma más intensa a discrecionalidad pública, de forma tal que su derecho de libertad de empresa se encuentra limitado de acuerdo con fines que se consideran legítimos. Ello encuentra su lógica al caracterizar a estos prestadores privados como el medio que utiliza el Estado — como único titular de la actividad — para asegurar una efectiva prestación de un servicio público bajo parámetros de calidad y eficiencia predeterminados y que aseguren la continuidad en la prestación del servicio al usuario final ${ }^{2}$. El servicio público se manifiesta en la regulación pública de la actividad; es decir, en la posibilidad en cabeza del Estado de controlar y regular la prestación misma del servicio para que se cumpla con los fines tenidos en cuenta al momento de decidir sujetar una determinada actividad a dicho régimen ${ }^{3}$.

Esta actividad de control estatal sobre los prestadores privados de los servicios públicos tiene especiales características que la diferencian de la actuación de la administración en sectores no sujetos al régimen del servicio público, pues, desde un punto de vista teleológico, se tiene como principal finalidad el satisfacer una necesidad pública en concurrencia con los particulares ${ }^{4}$. Dicho de otro modo, estamos ante una forma de intervención de la administración en la economía que tiene por finalidad garantizar la prestación de un servicio público para particulares y a través de particulares.

Así, es claro que el servicio público es una actividad jurídica de garantía y no una actividad material de prestación. La prestación del servicio público — en el marco del proceso de liberalización de la economía - se encuentra a cargo de los particulares, y el rol del Estado es garantizar que ellos realicen dicha actividad de forma tal que satisfaga las exigencias del interés público. En tal medida, el régimen del servicio público se encuentra cualitativamente en un nivel más intenso de intervención que la actividad de policía tradicional, entendida genéricamente como la actividad de mantenimiento del orden público mediante técnicas de limitación y coacción. El régimen del servicio público se sirve de las técnicas de la actividad de policía — entendidas estas como los medios que

1 «La importancia y utilidad práctica de la publicatio radica esencialmente en instaurar una especie de habilitación legal previa y conocida por los prestadores de turno, permitiendo de ese modo la participación estatal a través de la función de contralor y de regulación, sin provocar inseguridad jurídica y sin desestabilizar las prestaciones" (MAURO NALLAR, Daniel. Regulación y control de los servicios públicos. Buenos Aires: Marcial Pons, 2010, p. 203).

2 «El servicio público se concibe como una actividad de prestación basada en la idea de que la Administración se reservaba en todo caso la titularidad de la actividad (y a eso se denominaba publicatio), mientras que el ejercicio de esa actividad podría ser igualmente reservado a la esfera de la administración o ser concedido a los particulares [...] Bajo la perspectiva de la finalidad (y no de los medios utilizados) no se trata, en absoluto, de prestar un determinado servicio sino de garantizar su prestación» (VILLAR EZCURRA, José Luis. Derecho administrativo. Especial de administración pública y actividad de los particulares. Madrid: Civitas, 1999, p. 35).

3 MAURO NALLAR, Daniel. Ob. cit., nota 1, pp. 204-207.

4 VilLaR EZCURRA, José Luis. Ob. cit., nota 3, p. 34. 
utiliza la administración para actuar - otorgados mediante potestades específicas. Técnicas como las medidas de policía administrativa se utilizan de forma indistinta ${ }^{5}$ en ambas formas de intervención.

$\mathrm{Al}$ respecto, considerando que la actividad de policía consiste en la ejecución de las leyes formales que — en razón del interés general — limitan los derechos de los particulares ${ }^{6}$, es clara su vinculación con el régimen del servicio público. No es materia del presente ensayo realizar un análisis de las críticas dirigidas hacia el concepto de actividad de policía; bastará con mencionar que es un principio básico de cualquier ordenamiento jurídico y que no existe derecho que tenga carácter absoluto, pues deben respetarse los límites impuestos por otros derechos y por las normas que tienen por objetivo preservar bienes jurídicos valiosos para la sociedad. Por ello, es pertinente mencionar que «el poder de policía no es solo la limitación de derechos sino la tutela de otros derechos y del interés general»?

\section{I.1. Análisis económico: la organización de la produc- ción y el problema del principal-agente aplicado a la prestación de servicios públicos}

Las definiciones presentadas de servicio público y de poder de policía, así como la articulación existente entre ambos conceptos, son susceptibles de ser analizadas desde una perspectiva económica. En la medida que la actividad del servicio público se encuentra encaminada a garantizar la prestación de un determinado servicio de contenido económico a través de una «colaboración» entre la administración y el prestador, es pertinente analizar aquellos aspectos referidos a la organización de la producción que pueden resultar relevantes.

En el régimen del servicio público, en última instancia, se busca la producción de bienes y servicios a los que se ha investido de una especial relevancia. Para organizar la producción, las empresas utilizan conjuntamente dos sistemas: el sistema de órdenes y el sistema de incentivos. A continuación, se presenta una breve descripción de ambos ${ }^{8}$.

El sistema de órdenes es un método de organización de la producción que se articula sobre la base de una jerarquía gerencial en la cual las órdenes se transmiten hacia abajo a través de la jerarquía y la información se transmite hacia arriba por la misma vía. Los gerentes recopilan la información referida al desempeño y deciden las órdenes a

5 Ibíd., pp. 37-38.

6 OMAR CANDA, Fabián. «Régimen jurídico de la actividad de policía». En Servicio público, policía y fomento. Jornadas organizadas por la Facultad de Derecho de la Universidad Austral. Buenos Aires: Ediciones RAP, 2003, p. 3.

7 Ibíd., p. 11.

8 PARKIN, Michael. Economía. Sexta edición. México D.F.: Pearson Educación, 2004, pp. 197-198.

MEDIDAS

DE POLICÍA

ADMINISTRATIVAY

RÉGIMEN JURÍDICO

DEL SERVICIO

PÚBLICO: USO

DE LAS MEDIDAS

CORRECTIVAS EN EL

PERÚ 
emitirse y la forma de ponerlas en práctica9 ${ }^{9}$ El problema de este sistema radica en que la información disponible para los gerentes generalmente resulta incompleta, lo cual les dificultan tomar buenas decisiones y emitir órdenes que permitirán el uso eficiente de recursos. Aquí entra a tallar el sistema por incentivos.

De otra forma, el sistema por incentivos busca introducir a la empresa una serie de mecanismos similares a aquellos presentes en el mercado. No se emiten órdenes, sino que se implementan mecanismos de compensación e incentivos para inducir a los trabajadores a que se desempeñen de tal forma que se maximicen los beneficios de la empresa ${ }^{10}$.

Las empresas utilizan una mezcla de ambos sistemas para organizar su producción y eligen darle preponderancia a aquel sistema que permita maximizar sus beneficios. El factor que determina la preponderancia de uno u otro sistema es el costo de la supervisión y el costo de las consecuencias posibles de un mal desempeño.

Por otro lado, la elección del sistema se encuentra influenciada también por la existencia del problema del principal-agente. El problema principal-agente parte por reconocer que los agentes persiguen sus propios objetivos de acuerdo con sus intereses, lo cual impone costos sobre el principal. A la vez, sin embargo, el beneficio del principal depende del desempeño del agente. La solución a este problema consiste en la creación de reglas de compensación que induzcan al agente a actuar en el mejor interés del principal, como, por ejemplo, copropiedad de beneficios, pago de incentivos, contratos a largo plazo, entre otros.

Para explicar con mayor claridad lo señalado precedentemente, es pertinente revisar el concepto de los modelos de agencia aplicados al análisis económico del Derecho. La relación de agencia es una relación en la cual una persona (el principal) se beneficia cuando otra persona (el agente) realiza alguna tarea con esmero o esfuerzo ${ }^{11}$. Para asegurar que el agente realice su labor de acuerdo con las expectativas del principal se utiliza un sistema de incentivos. En el ámbito del Derecho privado, los incentivos pueden encontrarse en un contrato, mientras que, en el ámbito del Derecho público, los incentivos deben encontrarse en el marco

9 «Los militares utilizan el sistema de ordenes en su forma más pura. El comandante en jefe (el presidente o el ministro de defensa de un país) toma las grandes decisiones sobre los objetivos estratégicos. En el nivel inmediato inferior, los generales organizan sus recursos militares. Debajo de los generales, los sucesivos grados inferiores organizan unidades cada vez más pequeñas y atienden los detalles sucesivamente menores de cada una de las decisiones. En la parte más baja de la jerarquía están las personas que operan los sistemas de armamento» (Ibíd.).

10 «Las organizaciones que se dedican a las ventas son las que más utilizan los sistemas de incentivos. Los vendedores que pasan solos la mayor parte de su tiempo de trabajo y sin supervisión, son inducidos a trabajar intensamente al pagarles un salario pequeño y una gran prima relacionada con su desempeño» (Ibíd.).

11 POSNER, Eric. «Modelos de agencia en el análisis económico del Derecho». En Materiales de enseñanza del curso de Análisis Económico del Derecho. Lima: Publicaciones para la docencia PUCP, 2009, p. 171. 
regulatorio. El principal se beneficia cuando el agente realiza una tarea con debido cuidado y dando su mayor esfuerzo, pero el agente únicamente hará su mejor esfuerzo si se le compensa adecuadamente por ello. Cuando el principal no puede supervisar al agente adecuadamente surge el riesgo moral. La diferencia entre el esfuerzo deseado por el agente y el esfuerzo realizado por el agente se conoce como los costos de agencia ${ }^{12}$.

En este punto, regresamos a nuestro análisis de los sistemas de organización de la producción. Las formas de reducir los costos de agencia son, precisamente, el uso de incentivos y la inversión en sistemas de control. Aplicando nuestro análisis al sistema del Derecho administrativo —en especial al régimen del servicio público y a la actividad de policía-, queda claro que la administración, el particular prestador del servicio y el ciudadano-usuario se encuentran inmersos en una cadena de relaciones de principal agente. La administración resuelve los problemas de agencia que surgen entre el usuario y la empresa prestadora, por lo que a su vez asume el papel de principal respecto de esta última ${ }^{13}$.

Si se tiene como premisa lo señalado previamente, no cabe duda de que existe una necesidad de dotar a la administración de instrumentos de actuación flexibles, que le permitan implementar un sistema tanto de órdenes como de incentivos, para maximizar así el bienestar social en el marco de la prestación de un determinado servicio público, pero sin perder de vista el marco constitucional dentro el cual se desenvuelve. Dichos instrumentos encuentran su expresión normativa en el régimen jurídico del servicio público, en el poder de policía y, en gran medida, en la potestad de autotutela de la administración pública.

Por lo tanto, el Derecho administrativo debe contemplar la existencia de instrumentos que permitan a la administración — como principaltener una dirección y un control sobre la conducta del agente y que consideren a este último, asimismo, como titular de derechos constitucionales que no pueden ser desconocidos. Pasaremos ahora a efectuar un análisis de dichos instrumentos: las sanciones como mecanismo de desincentivo - las sanciones tienen por sobre todo un fin preventivoy, principalmente, las medidas de policía administrativa como mecanismo de emisión de órdenes. Veremos cómo este instrumento ha sido utilizado para paliar deficiencias de flexibilidad en la actuación de la administración.

\footnotetext{
12 lbíd., p. 176.

13 Esta situación responde, además, al fenómeno económico del denominado contrato eficiente, un contrato que - por definición- es siempre incompleto. La labor de los organismos reguladores en el ejercicio de su potestad reglamentaria es «completar» dichos contratos para mantener su eficiencia, y para esto necesita que su agente, que se encuentra en mejor posición de conseguir la información sobre el negocio en la práctica, le brinde los datos necesarios para cumplir con su labor. Por ello, es necesario que el organismo regulador implemente mecanismos adecuados para la obtención de esta (Véase: MAURO NALLAR, Daniel. Ob. cit., nota 1, p. 220).
}

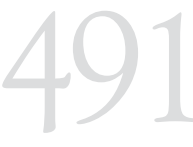

MEDIDAS

DE POLICÍA

ADMINISTRATIVAY

RÉGIMEN JURÍDICO

DEL SERVICIO

PÚBLICO: USO

DE LAS MEDIDAS

CORRECTIVAS EN EL

PERÚ 


\section{POTESTAD SANCIONADORA DE LA ADMINISTRACIÓN Y EL PRINCIPIO DE TIPICIDAD: ALGUNOS PROBLEMAS}

Son considerables las investigaciones que se han realizado desde distintas tradiciones jurídicas y desde la economía para determinar cuál es la forma más adecuada para implementar una política regulatoria en los sectores sujetos a monopolios naturales —que generalmente se identifican con aquellos sujetos al régimen del servicio público—. Aún existe polémica en lo que se refiere a cuáles son o deben ser los incentivos y hasta dónde debe llegar el sistema de control implementado por la administración respecto de los particulares que actúan en un mercado regulado. En este ensayo analizaremos únicamente el aspecto referido a la potestad sancionadora de la administración; es decir, la posibilidad de imponer sanciones del más amplio espectro y la potestad de la administración de ordenar otras medidas de policía administrativa diferentes de la sanción.

El ordenamiento de la potestad sancionadora estatal es una necesidad del cambio de paradigma respecto a las funciones que debe cumplir el Estado, especialmente en materia de servicios públicos. El Estado predominantemente supervisor necesita de un marco adecuado para supervisar, fiscalizar y controlar la actividad de los particulares, que a la vez garantice las libertades económicas que estos ostentan y que tienen como fuente a la Constitución. Ello debido a que, cuando nos referidos a la potestad sancionadora de la administración, «nos encontramos frente a la potestad más aflictiva con que cuenta la Administración para legítimamente gravar patrimonio, limitar o cancelar derechos o imponer restricciones a las facultades ciudadanas $[\ldots]{ }^{14}$.

La potestad sancionadora es claramente el más intenso instrumento para desincentivar y controlar las conductas de los particulares. Específicamente, «la potestad sancionadora constituye una competencia de gestión necesaria complementaria a la potestad de mando y corrección para el adecuado cumplimiento del orden administrativo establecido en procura del interés público» ${ }^{15}$. Considerando ello, es importante destacar una característica importante de la potestad sancionadora, aquella que nos dice que, «a diferencia de las demás actividades de la administración, la actividad sancionadora tiene un objetivo único: ejercer la pretensión sancionadora del poder público administrativo mediante un procedimiento especial donde el administrado tenga las suficientes garantías para el ejercicio de su defensa» ${ }^{16}$.

Tomando en cuenta dichas características, el uso de esta potestad debe ser de ultima ratio en el ejercicio de la función administrativa que debe

14 Morón URBinA, Juan Carlos. «Comentarios a la Ley del Procedimiento Administrativo General». Gaceta Jurídica, 2007, p. 629, Lima.

15 lbíd.

16 lbíd., p. 631. 
privilegiar herramientas que surgen de la «potestad de mando y corrección» - conocida en la teoría jurídica como regulación social o poder de policía de la administración-, distintas de la imposición de una sanción. Es importante delimitar de forma clara cuándo es necesario recurrir al ejercicio de la potestad sancionadora y cuándo es suficiente recurrir a otras formas de control.

El ejercicio de la potestad administrativa sancionadora en el Perú se encuentra sujeta a los principios de la Ley del Procedimiento Administrativo General —en adelante, LPAG-. Para efectos del presente ensayo, cobra especial relevancia el denominado principio de tipicidad. El referido principio prescribe, entre otros, la exigencia de certeza o exhaustividad suficiente en la descripción de las conductas sancionables constitutivas de infracciones administrativas. Al respecto, se señala lo siguiente:

[...] las conductas sancionables administrativamente únicamente pueden ser las infracciones previstas expresamente mediante la identificación cierta de aquello que se considera ilícito para los fines públicos de cada sector estatal. En este sentido, la norma legal debe describir específica y taxativamente todos los elementos de la conducta sancionable, reduciendo la vaguedad del enunciado sancionable de modo que tanto el administrado como la administración prevean con suficiente grado de certeza (lex certa) lo que constituye el ilícito sancionable $[. . .]^{17}$.

El principio de tipicidad bajo esta perspectiva busca preservar la autonomía de los administrados (principio de libertad) «representada por la capacidad de elegir y ejecutar libremente sus actividades sociales y económicas con la garantía y seguridad de ser lícitas y no ser pasibles de sanciones inadvertidas previamente» ${ }^{18}$. Un ejemplo de contravención al principio de tipicidad es establecer como sanción, de forma genérica, «el incumplimiento de las normas establecidas en la presente ley y su reglamento» ${ }^{19}$. Este tipo de enunciados son una muestra de una disposición sancionadora en blanco, que no define de manera cierta la conducta sancionable.

Distinto es el supuesto de utilización de conceptos jurídicos indeterminados. La tipificación indirecta es una forma de atenuar los riesgos de sobreinclusión o infrainclusión de conductas sancionables en las normas sancionadora $^{20}$. Se habla de tipificación indirecta del ilícito administrativo

17 MORÓN URBINA, Juan Carlos. «Los principios delimitadores de la potestad sancionadora de la administración pública en la ley peruana». Advocatus Nueva Época, número 13, 2005, p. 6, Lima. 18 lbíd., p. 7.

19 Véase: STC 2192-2004-AA/TC y STC 3256-2004-AA/TC.

20 «En aspectos administrativos, no es aconsejable llevar a extremos el mandato de tipificación, pues estaríamos frente a casuismos inconvenientes. Los riesgos evidentes son dos extremos perniciosos: la sobreinclusión (inclusión dentro de la tipificación de supuestos específicos que no participan de la necesidad de sanción), pero en el otro extremo tenemos la infrainclusión (exclusión de supuestos que si deberían ser sancionables). Ambos riesgos se producen por dos vicios extremos del legislador 
cuando los elementos constitutivos de la sanción se encuentran disgregados en normas distintas. Se concreta a través de tres preceptos: (i) elemento del tipo que establece un mandato o prohibición para el administrado, (ii) elemento del tipo que califica como infracción el incumplimiento del mandato o prohibición, y (iii) elemento del tipo referido a la sanción aplicable $^{21}$.

En favor de la tipificación indirecta se afirma que, desde una perspectiva funcional del Derecho, permite superar la imposibilidad de predeterminar todas las conductas que pueden resultar sancionables, sin dejar pasar aquellas conductas que pueden resultar no deseadas socialmente ${ }^{22}$. Sin embargo, si bien es cierto que existe una necesidad de reconocer la inabarcabilidad de la casuística, este argumento parte por asumir que la sanción es la única forma de actuación que tiene la administración para reprimir conductas, cuando, en la realidad, esto no solo es falso, sino que desconoce la naturaleza de ultima ratio de la potestad sancionadora.

La tipificación indirecta es una técnica que otorga a la administración la posibilidad de ampliar el espectro de supuestos de hecho pasibles de ser sancionados. Los beneficios de dicha técnica deben ser confrontados con el hecho que la labor principal de la administración es más cercana a la idea de gestión que a la de mera persecución. Si bien es cierto que se trata de una herramienta que pretende permitir más flexibilidad en la persecución de conductas no deseables socialmente, consideramos que tiene algunos problemas en su aplicación: (i) sus límites son cuestionables y desconoce la calidad de ultima ratio de la potestad sancionadora; (ii) los parámetros para su utilización muchas veces no son entendidos correctamente por la administración, lo que, en los hechos, repercute en la proliferación de disposiciones sancionadoras en blanco; y (iii) para que sea legítima, de una forma u otra, se requiere que en una normas se establezca el mandato o prohibición de forma exhaustiva y expresa, lo cual nos regresa al problema de la imposibilidad de prever toda conducta a la que se quiera aplicar una sanción.

al tipificar. Cuando acude a fórmulas demasiado generales, por el recelo a no incluir supuestos reprochables, se propicia la posibilidad de sobreincluir conductas menores o simplemente que no deberían ser sancionables. Por el contrario, cuando se acuden a fórmulas más específicas y detalladas, se asume el riesgo de reprochar menos supuestos de los debidos, por ser igualmente indebidos" (MORÓN URBINA, Juan Carlos,. Ob. cit., nota 19, p. 9).

21 lbíd., p. 9.

22 «[...] bajo el pretendido argumento de la seguridad jurídica, se pretende extender el alcance de la tipificación de infracciones y sanciones administrativas hasta el punto de situar a la Administración Pública frente a dos alternativas: o se pone bajo la espalda la tarea imposible de predeterminar, de manera anticipada, la totalidad de conductas sobre las que resulta posible aplicar una sanción; o, se ubica cómodamente de manera implícita del lado del infractor, limitándose a reprimir sólo aquellas conductas que se encuentren tipificadas de manera taxativa en una norma sancionadora, con el consecuente resultado de dejar sin respuesta una gran proporción de comportamientos no deseados socialmente, los que, por no encontrarse tipificados expresamente, continuarán desarrollándose sin que sus consecuencias perjudiciales puedan ser enervadas por la acción administrativa» (MELGAR CÓRDOVA, Eduardo. "Quien mucho abarca poco aprieta: algunas consideraciones a favor de la utilización de la tipificación indirecta en el derecho administrativo sancionador». Revista de Derecho Administrativo, CDA, número 2, diciembre, 2006, p. 274, Lima). 
Llevar al extremo la técnica de la tipificación indirecta puede conducir a su completa desnaturalización. Aun en el caso de que sea bien utilizada, es una técnica que puede derivar en un sobredimensionamiento del Derecho administrativo sancionador.

Así, debe evaluarse si las medidas de policía administrativa, utilizadas de forma correcta, son una alternativa válida para enfrentar los problemas que pretenden solucionarse con mecanismos como la tipificación indirecta. Dichas medidas son la herramienta con que cuenta la administración para emitir órdenes en oposición a imponer sanciones. Pasaremos exponer el concepto de medida de policía administrativa.

\section{II.1. Sanción, medidas de policía administrativa y medi- das correctivas: conceptualización}

Iniciaremos nuestro análisis de las medidas de policía administrativa distinguiéndolas de las sanciones. Cabe resaltar que, en nuestro país, son casi inexistentes las investigaciones sobre este tipo de medidas, a pesar de que vienen siendo utilizadas con mayor frecuencia por las entidades estatales. En los siguientes párrafos haremos un recuento del desarrollo doctrinal existente sobre medidas de policía administrativa, sobre la base de las llamadas «medidas provisionales» existentes en el ordenamiento jurídico español y que son equivalentes a las medidas cautelares en sede administrativa recogidas en la normativa peruana. Como veremos, los autores se han detenido a reflexionar acerca de la naturaleza de este tipo de medidas y han concluido que, entre ellas y las medidas de policía administrativa, existen considerables diferencias ${ }^{23}$. Al respecto:

23 «Salvo la denominación de medidas provisionales, es muy frecuente encontrar previsiones normativas que contemplan todo tipo de medidas directamente encaminadas a la tutela del interés público presente en cada caso. Incluso, a veces, más que medidas provisionales se trata de verdaderas medidas de policía. Estas circunstancia apuntada no es más que una muestra de confusión entre las medidas de policía, en muchos casos denominadas medidas cautelares, y las medidas provisionales en sentido estricto, pese a que ambas figuras responden a un significado y a una finalidad diferentes» (MARINA JALVO, Belén. Medidas provisionales en la actividad administrativa. Valladolid: Lex Nova, 2007, p. 22). «No obstante, el ordenamiento jurídico recoge también la existencia de determinadas medidas que no persiguen necesariamente tal finalidad. Como se ha indicado, no son instrumentales de otra resolución, sino directamente del interés público que en cada caso persigan. Tienen de cautelar el que se adoptan como reacción ante ciertos riesgos o perturbaciones y suponen, por su contenido y fines, cautelas para evitar lesiones al interés público protegido o para impedir la continuación de sus efectos antijurídicos. [...] son medidas de policía administrativas [...] o actos que tienen por finalidad el restablecimiento del ordenamiento jurídico conculcado [...]; y a lo sumo cabe decir, [...] que se trata simple medida dirigida a hacer desaparecer una situación que se reputa ilegal y que [...] la urgencia con que se pensaba que era necesario aplicar la medida la dota en cierto modo de una naturaleza cautelar. Estas medidas tienden de forma inmediata al restablecimiento del orden jurídico perturbado y se dirigen a la congelación de la situación de hecho. Por tanto, se trata de medidas de coacción administrativa directa caracterizadas por el empleo de la fuerza en el desarrollo de funciones administrativas, motivada por una situación de urgencia, que legitima la acción inmediata con fundamento en una decisión no procedimentalizada, la cual, en todo caso, se encuentra sometida al principio de legalidad y guiada por los principios de oportunidad, congruencia y proporcionalidad» (GARCíA URETA, Agustín. La potestad inspectora de las administraciones públicas. Madrid: Marcial Pons, 2006, pp. 145-146). 
En sede de principio, por tanto, es posible distinguir tales medidas de policía administrativa de las que se englobarían en el contexto de las provisionales. Estas últimas vendrían a suplir interinamente la falta de una resolución que aún no se ha producido o, incluso, un procedimiento que ni siquiera ha comenzado. En las primeras, estaría ausente tal conexión procedimental, siendo su finalidad la de garantizar el orden frente a peligros que se susciten y sin necesidad de encontrarse relacionados con un procedimiento sancionador [...] De hecho, se reconoce que concurren en las medidas provisionales finalidades que no encajan exactamente con la de asegurar la resolución que pudiera recaer, surgiendo medidas provisionales que están conectadas con la finalidad última, pero no tienden propiamente a garantizar su eficacia o ejecución, que incluso puede que no esté en peligro. Esta circunstancia hace que el régimen jurídico de ambos tipos de medidas resulte similar, y que puedan servir a los objetivos generales de la inspección $[\ldots]^{24}$.

Las medidas de policía administrativa tienen una configuración y finalidad propia, cuyo origen es, en principio, la noción de «orden» entendida como un mandato dirigido al administrado que tiene como fuente un acto emitido por la administración. En efecto, imponer una sanción no es la única forma que tiene la administración para cumplir con poner en vigencia el ordenamiento jurídico, sino que, por el contrario, es el último recurso al que debe acudir. Así, «la vulneración del ordenamiento jurídico puede dar lugar a distintas consecuencias que [...] pueden clasificarse en dos categorías distintas: (i) la imposición de una sanción, si aquella está tipificada como infracción y (ii) la restauración del orden jurídico perturbado» ${ }^{25}$. Esta segunda posibilidad se encuentra fundamentada plenamente no en una tipificación específica, sino en el contenido prescriptivo-imperativo de una norma jurídica. La administración, como gestora y tutora del interés público, debe estar facultada para hacer cumplir a los administrados sus obligaciones legales. Ese mandato, a diferencia de la sanción, busca el cumplimiento material de aquello establecido en la norma.

La posibilidad de emitir medidas de policía tiene una estrecha relación con la potestad de inspección de la administración, así:

[...] Uno de los efectos de la actividad de constatación o verificación es identificar los incumplimientos de las condiciones o requisitos normativos o técnicos. En tales casos, el ejercicio de la función de inspección puede derivar en el ejercicio de la potestad sancionadora o inclusive en el surgimiento de responsabilidades adicionales, como son las obligaciones de reposición de cosas a su estado primitivo, restauración de objetos, reparación de daños o pago de indemnizaciones debidas $[\ldots]^{26}$.

24 lbíd.

25 CASINO RUBIO, Miguel. «La indebida confusión entre sanciones y otras medidas administrativas de policía: comentarios a la STS del 2 de febrero de 1998, artículo 2060 ». Reala, número 283, mayoagosto, 2000, p. 571.

26 MORÓN URBINA, Juan Carlos. Ob. cit., nota 16, p. 631. 
Estas responsabilidades adicionales —entendemos - se dan por la existencia de un incumplimiento de disposiciones normativas detectado en la verificación. En efecto, durante una inspección, además de detectar infracciones, puede establecerse que existen incumplimientos de normas que no necesariamente se encuentran comprendidas en un tipo sancionador: «Del ejercicio de la potestad inspectora pueden derivarse medidas que pretendan atajar tanto posibles infracciones como, en general, situaciones que se desvíen de lo que la norma exija en cada momento, ya sea la protección del consumidor o la del ambiente, o la salud de las personas. Debido a esto, se habilita a la administración para poder adoptar medidas que salgan al paso de esas circunstancias» ${ }^{27}$.

Sin embargo, la distinción entre las medidas de policía y las sanciones no siempre resulta clara ${ }^{28}$. La sanción administrativa es un mal infringido por la administración a un administrado por incurrir en una conducta ilegal ${ }^{29}$. Las sanciones deben tener un contenido aflictivo, deben consistir en un perjuicio al ciudadano impuesto como un castigo; es decir, buscado directa y deliberadamente. Asimismo, se trata de actos constitutivos en la medida que modifican la situación jurídica del administrado ${ }^{30}$. Lo que distingue a una sanción de otro tipo de medidas es que tiene como finalidad inmediata la de causar un daño al administrado. $\mathrm{Al}$ respecto, se señala que «ese mal no sirve para restablecer la legalidad o la realidad física alterada o los valores lesionados, ni para compensar el daño producido, ni para imponer la conducta correcta. Todo esto, por el contrario, es lo característico de otras decisiones administrativas que no son sanciones administrativas propiamente dichas, por lo que no tiene ningún sentido aplicarles el régimen respectivo» ${ }^{31}$.

Es importante tomar en cuenta que la imposición de una sanción únicamente tutela el interés público de forma mediata. La sanción no impone de forma directa la conducta correcta al administrado. Por ello, la administración, haciendo uso únicamente de la potestad sancionadora, se

27 García URETA, Agustín. Ob. cit., nota 25, pp. 144-145.

28 «Una primera dificultad surge, sin embargo, cuando aquella [una orden] sirve potencialmente a ambos señores y es alternativamente según los casos, sanción o medio para reparar el orden quebrantado. Cuando esto sucede, la verdadera naturaleza y contenido de la decisión en cada caso considerada se convierten en un criterio principalísimo» (CASINO RUBIO, Miguel. Ob. cit., nota 27, p. 571).

29 «El concepto más difundido de sanción administrativa ha sido aportado por Eduardo García de Enterría quien la define como un mal infringido por la administración a un administrado como una conducta ilegal» (DANÓs ORDOÑEZ, Jorge. «Notas acerca de la potestad sancionadora de la administración pública». Ius et Veritas, número 10, julio, 1995, p. 156, Lima).

30 «Desde esta última perspectiva, las sanciones administrativas son siempre, en cualquiera de sus formas de naturaleza constitutiva y de contenido aflictivo. Instituyen al infractor en una posición jurídica nueva o distinta y, además, desfavorable respecto a la de que aquel disfrutaba antes de cometer la infracción. Esta nueva situación consiste, típica y principalmente en la imposición de una obligación de pago, y/o en la perdida (total o parcial, definitiva o temporal), de una situación subjetiva favorable constituida por el derecho administrativo acordadas en el ejercicio de la correspondiente potestad sancionadora y siempre con un fin punitivo" (CASINO RUBIO, Miguel. Ob. cit., nota 27, p. 571).

31 Véase: Rebollo Puig, Manuel, Manuel IzQUiERdo CarRasco, Lucía AlaRcón Sotomayor y Antonio BUENO ARMIJO. «Panorama del derecho administrativo sancionador en España: los derechos y las garantías de los ciudadanos». Revista Estudios Socio-Jurídicos, Universidad del Rosario, número 1, enero-junio, 2005, p. 25, Bogotá. 
encontraría imposibilitada de tutelar adecuadamente el interés público. Es allí donde existe la necesidad de otro tipo de actuación, como la utilización de las medidas de policía administrativa, las cuales - a diferencia de las sanciones - tienen calidad declarativa ${ }^{32}$ en tanto no modifican la situación jurídica del administrado:

Por el contrario, las medidas de tipo reparatorio, aun cuando traen causa también de un incumplimiento previo, son simplemente declarativas del régimen jurídico sustantivo de referencia no respetado o incumplido, y su contenido, limitado por eso mismo a restablecer la situación indebidamente alterada, carece de todo contenido aflictivo, sin añadir ni quitar nada a la posición jurídica del infractor. Y son, por ello también independientes y compatibles, en su caso, con la imposición de la sanción que proceda $[\ldots]^{33}$.

Profundizando en este punto, «para que realmente se trate de un castigo es necesario, primero, que altere la situación jurídica de quien lo sufre perjudicándole y, segundo, que ese perjuicio sea precisamente buscado como tal directa y deliberadamente $[\ldots] \aleph^{34}$. En el mismo sentido, debe mencionarse lo siguiente:

Además, el perjuicio en que la sanción consiste está previsto e impuesto como tal, como un mal. Es decir, las previsiones sancionadoras del ordenamiento y los actos administrativos que imponen una sanción determinada buscan directa, precisa y deliberadamente causar el mal en que consisten: el concreto mal que se causa es inútil para los intereses generales, en el sentido de que no los satisface o los realiza [...] Este mal no sirve para restablecer la realidad física alterada o los bienes jurídicos lesionados por la infracción ni para compensar el daño que haya causado ni para imponer al infractor la conducta conforme al ordenamiento o conveniente para los intereses generales [...] todo esto por el contrario es lo propio de otros actos administrativos de gravamen muy diversos entre sí [...] y para los que el régimen particularmente garantista de las sanciones es por completo inadecuado pues supondría crear obstáculos injustificados para la realización de los intereses generales ${ }^{35}$ (las cursivas son nuestras).

La finalidad de las sanciones es entonces meramente preventiva. «Las sanciones tienen una finalidad [...], son útiles como sistema de respaldo o tutela del ordenamiento, pues sirven para prevenir infracciones futuras y, así, aunque sea de manera indirecta, proteger los intereses públicos

32 «No caben sanciones beneficiosas ni neutras. Además ha de tratarse de un perjuicio que derive exactamente de la sanción. Por tanto, no será sanción la negación de un derecho que no se tenía ni la imposición de un deber que ya existía» (REBOllo PUIG, Manuel. «El contenido de las sanciones». Revista Justicia Administrativa. Editorial Lex Nova, 2000, p. 162).

33 Casino Rubio, Miguel. Ob. cit., nota 27, pp. 571-572.

34 Rebollo Puig, Manuel. Ob. cit., nota 34, p.155.

35 lbíd. 
confiados a la administración» ${ }^{36}$. Sin embargo, no suplen la necesidad de un mecanismo de tutela directo ${ }^{37}$. La emisión de órdenes, mandatos y/o medidas dirigidas al administrado, imponiéndole una determinada conducta, es una potestad necesaria para el adecuado ejercicio de la función administrativa y, por ende, podemos decir que estamos ante una potestad implícita en el concepto de función administrativa, pues si una norma prescribe una conducta que luego es incumplida, la administración debe poder obligar al administrado a corregir su actuar. Aquí es necesario precisar, sin embargo, la relación necesaria entre la orden emitida y el contenido de la norma. Es el contenido prescriptivo de la norma el que legitima el actuar de la administración y, a la vez, representa su límite lógico. No obstante, es claro que existe una necesidad de sujetar la emisión de medidas de policía administrativa a la existencia de un acto formal y a una serie de principios que aseguren su razonabilidad ${ }^{38}$. Sobre esto abundaremos más adelante.

La posibilidad que tiene la administración de emitir y hacer cumplir sus órdenes proviene de la denominada autotutela ejecutiva; es decir, aquella potestad para hacer cumplir y ejecutar de forma autónoma sus decisiones, ya que «sucede siempre que hay un incumplimiento. Para obtener el respeto de lo ordenado o prohibido en la norma, no siempre es preciso que la administración eche mano de su potestad sancionadora. En ocasiones, como ha recordado Nieto [...], sobra con que simplemente ponga en marcha sus prerrogativas de autotutela ejecutiva ${ }^{39}$.

Así, por ejemplo, ante la existencia de un local que viene operando sin la obligatoria licencia de funcionamiento lo correspondería. Al respecto, dice el mismo texto que «naturalmente, para ordenar el cierre de un establecimiento que funciona sin la correspondiente autorización administrativa, la administración no necesita echar mano de su potestad sancionadora. Sobra con que simplemente ponga en marcha sus prerrogativas de autotutela ejecutiva y, en su virtud, concrete —actualizando con carácter meramente declarativo- la prohibición normativa del ejercicio de la actividad sin previa autorización administrativa» ${ }^{40}$.

36 lbíd., p. 157.

37 «El fundamento último de una y otra decisión es, pues, bien distinto. En uno, represor del incumplimiento; en el otro, reparador de este (rectius de su resultado). En otras palabras, las sanciones administrativas castigan la perturbación, infligiendo un mal que no restablece el orden quebrantado por la infracción; las medidas reparatorias la remedian, restituyendo las cosas a su estado anterior» (CASINO RUBIO, Miguel. Ob. cit., nota 27, p. 572).

38 «En todo caso, incluso en aquellos supuestos en los que la norma no llegue a concretar qué medidas cabe adoptar, la actuación administrativa no es libre, sino que permanece sujeta a un criterio de proporcionalidad y de racionalidad de su actuación. Tales principios, junto con otros de carácter reglado que acompañan al ejercicio de tal potestad, sirven de mecanismo de control del uso de la misma" (García UReTA, Agustín. Ob. cit., nota 25, p. 151). Asimismo, de la misma obra, viene también a colación la siguiente cita: «ha de existir una decisión sobre la adopción de las medidas, incluso en los casos de urgencia" (Ibíd., p. 153).

39 CASINO RUBIO, Miguel. Ob. cit., nota 27, p. 571.

40 lbíd., p. 572.

MEDIDAS

DE POLICÍA

ADMINISTRATIVAY

RÉGIMEN JURÍDICO

DEL SERVICIO

PÚBLICO: USO

DE LAS MEDIDAS

CORRECTIVAS EN EL

PERÚ 
La confusión existente entre las sanciones y las medidas de policía administrativa ha obstaculizado el uso adecuado de este tipo de medidas, pues no es claro el régimen al que deben sujetarse. $\mathrm{Al}$ respecto:

Las sanciones administrativas son conocidamente el instrumento típico de que dispone la Administración Pública para corregir las conductas contrarias al ordenamiento jurídico. Pero no son, desde luego, el único. Sin sancionar, la administración cuenta también con otros variados instrumentos para imponer el respeto a lo dispuesto en las normas. Distinguir las sanciones de aquellas otras medidas administrativas que, aun cuando con un contenido y función semejante, no pertenecen al campo del derecho administrativo sancionador es, bien se comprende, una cuestión principal. Por lo pronto, de ello depende la aplicación o el distanciamiento de los principios y garantías vinculados al ius puniendi del Estado $[. . .]^{41}$.

Sin embargo, la confusión entre las sanciones y las medidas de policía administrativa es bastante común. Los autores citados precedentemente señalan que:

[...] en la práctica se presentan casos dudosos y la frontera entre sanciones administrativas y otras decisiones administrativas perjudiciales para los ciudadanos no siempre es nítida. En realidad, hay decisiones administrativas con el mismo contenido aflictivo que pueden ser en unos casos sanciones y en otros no: dependen de que sean un castigo o no. Así la retirada de un permiso de conducir es una veces sanción administrativa y otras una medida para garantizar la seguridad del tráfico $[. . .]^{42}$.

Reiteramos que dichas confusiones tienen un efecto pernicioso en el sistema del Derecho administrativo. A mayor detalle:

[...] En la misma línea no debería preverse como sanción aquella media que impone a un administrado la conducta correcta [...] pero a veces el legislador - por su burda técnica, por obsesión sancionadora o por otras razones configura tales medidas como sanciones [...] Con tal error, no sólo no consigue imponer realmente un nuevo mal, sino que dificulta con requisitos impropios o excesivos (culpabilidad, tipicidad, procedimiento sancionador, inexistencia de prescripción, etc.) lo que debería poder acordarse con otra naturaleza y sin tales obstáculos $[. . .]^{43}$.

En resumen, luego del análisis funcional y doctrinal efectuado, podemos concluir que las medidas de policía administrativa tienen las siguientes características: 
- Son fundamentalmente expresión de una orden emanada de la administración.

- Son medidas que tutelan de forma directa el interés público.

- A diferencia de las medidas cautelares, no son instrumentales a otra resolución.

- Tienen por finalidad restablecer el orden jurídico incumplido; es decir, hacer desaparecer la situación contraria a la norma.

- Son medidas de coacción directa.

- No se encuentran procedimentalizadas.

- Se encuentran sometidas a los principios de proporcionalidad, congruencia, oportunidad y racionalidad.

- Su imposición no se encuentra relacionada necesariamente a la existencia de una infracción.

- No es necesario que se encuentren tipificadas, pues se fundamentan directamente en el contenido imperativo de una norma.

- Se encuentran relacionadas con la potestad inspectora de la administración.

- A diferencia de las sanciones, que tienen como finalidad inmediata castigar al administrado, las medidas de policía administrativa no tienen un contenido aflictivo y son declarativas, no tienen un fin preventivo, sino que tienen como finalidad inmediata la tutela del interés público.

- Son un necesario complemento a la potestad sancionadora y una alternativa menos gravosa ante la necesidad de flexibilidad. Por ello, la potestad para imponerlas es implícita a la función administrativa y proviene de la autotutela ejecutiva de la administración.

- No le son aplicables las disposiciones propias del Derecho administrativo sancionador, las cuales, por el contrario, obstaculizan su adecuado uso.

- En tanto se fundamentan en el contenido prescriptivo de una norma, es ese contenido el límite su configuración e imposición.

- Deben ser impuestas en un acto formal que cumpla con los requisitos de validez de todo acto administrativo.

- En tanto no cumple las mismas funciones que la sanción, ante la existencia de una infracción tipificada como tal, no puede considerarse que la imposición de esta medida sea alternativa a la imposición de una sanción.

\section{III.DISEÑO NORMATIVO DE LAS MEDIDAS CORRECTIVAS}

Con un concepto de medida de policía administrativa que ha sido debidamente delimitado, ahora aplicaremos los parámetros identificados

MEDIDAS

DE POLICÍA

ADMINISTRATIVAY

RÉGIMEN JURÍDICO

DEL SERVICIO

PÚBLICO: USO

DE LAS MEDIDAS

CORRECTIVAS EN EL

PERÚ 
para analizar las medidas correctivas en el ordenamiento jurídico peruano. Si bien sostenemos que la posibilidad de dictar medidas de policía administrativa es implícita al ejercicio de la función administrativa, en el Perú la tendencia ha sido otorgar de forma expresa la potestad de emitir medidas correctivas, sobre todo en el caso de los organismos reguladores y la autoridad de defensa de la competencia. Una excepción es el caso de los gobiernos locales, a los cuales, en principio, no se les ha otorgado de forma expresa dicha potestad, pues la Ley Orgánica de Municipalidades únicamente prevé una serie de medidas a título de sanción ${ }^{44}$, aunque de un análisis de dichas medidas algunas parecen configurarse como medidas correctivas — por ejemplo el retiro de elementos antirreglamentarios-.

La LPAG establece en su artículo 232 lo siguiente:

Artículo 232.- Determinación de la responsabilidad. 232.1 Las sanciones administrativas que se impongan al administrado son compatibles con la exigencia de la reposición de la situación alterada por el mismo a su estado anterior, así como con la indemnización por los daños y perjuicios ocasionados, los que serán determinados en el proceso judicial correspondiente $[\ldots]$.

La norma establece la posibilidad de emitir medidas de reposición de la situación alterada. Si bien, al parecer, se refiere a medidas que pueden ser ordenadas de forma concurrente a una sanción, creemos que la disposición admite una interpretación más amplia. El artículo reseñado establece un primer acercamiento normativo a la posibilidad que tiene la administración de ordenar medidas de reposición. Sin embargo, debe precisarse que una medida de policía, como se ha señalado, no necesariamente hace referencia a la reposición «a un estado anterior» sino, por el contrario, busca que se efectúe una conducta en cumplimiento de una norma que podría referirse a una conducta que nunca fue realizada. La redacción del artículo 232 de la LPAG ha distorsionado la forma como se han conceptualizado las medidas correctivas en los ordenamientos sectoriales.

Al respecto, por ejemplo, el reglamento del procedimiento administrativo sancionador del OSINERGMIN establece que, sin perjuicio de las sanciones a imponerse, el órgano competente podrá imponer medidas correctivas que permitan restablecer las cosas o situaciones alteradas por una conducta antijurídica a su estado anterior ${ }^{45}$.

Otra concepción errada ha sido desconocer la naturaleza directamente ejecutiva de las medidas correctivas. Ante el incumplimiento de una

44 «Ley 27972. Artículo 46.- Sanciones [...] Las sanciones que aplique la autoridad municipal podrán ser las de multa, suspensión de autorizaciones o licencias, clausura, decomiso, retención de productos y mobiliario, retiro de elementos antirreglamentarios, paralización de obras, demolición, internamiento de vehículos, inmovilización de productos y otras [...]”.

45 Véase el artículo 16 de la resolución de consejo directivo 233-2009-OS/CD. 
medida correctiva, en principio, la administración podría recurrir directamente a los mecanismos de ejecución forzada de los actos administrativos, como las multas coercitivas ${ }^{46}$. Por el contrario, en el reglamento de infracciones y sanciones del OSIPTEL se ha tipificado el incumplimiento de lo dispuesto en una medida correctiva como una infracción muy grave ${ }^{47}$. Esto tiene un efecto perjudicial en la medida correctiva en términos de la oportunidad de su cumplimiento.

En forma general, los organismos reguladores han acudido al uso de medidas correctivas cuando una conducta contraria al ordenamiento jurídico no se encuentra tipificada como sanción, al sustentarlo en la necesidad de recurrir a técnicas que permitan flexibilizar el mandato de tipificación de las sanciones. En ese sentido se indica que:

Para suplir en parte, las consecuencias de la impracticable tipificación total, el operador jurídico se ve obligado a emplear técnicas distintas a las sancionatorias, como es el caso de las medidas correctivas [...] a efectos de exigir el cumplimiento de aquellas obligaciones y mandatos cuya inobservancia no se encuentre tipificada. «[...] su exigencia [de la medida correctiva] no deriva de la aplicación de aquella; sino, en la mayoría de los casos, de la amenaza en ciernes del inicio de un futuro procedimiento administrativo sancionador [...] dicha medida no representa en la práctica una alternativa a la tipificación indirecta [...] toda vez que, al tratarse de un mecanismo carente de efectos coercitivos por sí mismo, necesita del auxilio de una sanción administrativa para su cumplimiento $[\ldots]^{48}$.

$\mathrm{Al}$ respecto, no se debe olvidar que la sanción por sí misma no «exige el cumplimiento» de las obligaciones legales — como se ha señalado reiteradamente en el presente ensayo-, y que, por el contrario, no hay razón para descartar las «técnicas distintas a las sancionatorias» como herramientas efectivas para lograr dicho objetivo. Considerando los problemas de agencia y demás — expuestos al inicio del presente ensayo-, la imposición de una sanción únicamente atiende al sistema de incentivos y no al de órdenes que es un complemento necesario y elemento insustituible para garantizar el interés público. Un ejemplo en ese sentido es el reglamento del procedimiento administrativo sancionador del OSINERGMIN, que además de otorgar la posibilidad de dictar medidas correctivas, reconoce la posibilidad de dictar mandatos. Así, la norma establece lo siguiente:

46 «Las multas coercitivas tienen como finalidad doblegar la resistencia de los administrados para el cumplimiento de una obligación. Lo característico de tales multas es la posibilidad de su repetición periódica [...] las multas coercitivas no tienen carácter punitivo, no se inscriben en el ámbito de la potestad sancionadora de la administración, porque se trata de medidas de constreñimiento económico para asegurar la ejecución forzosa de los actos administrativos, por esa razón las ubica con más propiedad como manifestaciones de la potestad de autotutela ejecutiva de la administración pública» (DANós ORDóÑEZ, Jorge. Ob. cit., nota 31, pp. 157-158).

47 Véase los artículos 62 y 63 de la resolución de consejo directivo 002-99-CD-OSIPTEL.

48 Melgar CoRdóva, Eduardo. Ob. cit., nota 24, pp. 300-301.

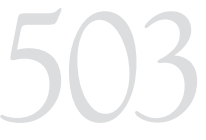

MEDIDAS

DE POLICÍA

ADMINISTRATIVAY

RÉGIMEN JURÍDICO

DEL SERVICIO

PÚBLICO: USO

DE LAS MEDIDAS

CORRECTIVAS EN EL

PERÚ 
[...] Artículo 19.- Mandatos o disposiciones de carácter particular del OSINERGMIN [...] El órgano competente podrá emitir mandatos o disposiciones fuera o dentro del procedimiento sancionador, cuando éstas sean necesarias para garantizar que el administrado actúe apegado a sus deberes o para evitar que se cometa o se continúe la comisión de un ilícito administrativo sancionable, así como para coadyuvar a las investigaciones preliminares, para obtener información a ser puesta a disposición del público o para resolver un expediente o caso sujeto a competencia del OSINERGMIN [...].

Por otro lado, la necesidad del «auxilio de una sanción administrativa para su cumplimiento» es un elemento que debe ser considerado de forma relativa pues tanto las medidas correctivas como las sanciones -en caso de ser incumplidas - pueden ser objeto de ejecución forzada. Los efectos coercitivos no están en la sanción o medida en sí mismas, sino en los mecanismos de ejecución con los que cuenta la administración.

Finalmente, debemos mencionar que, en general, en el concepto de medida correctiva como medida de policía administrativa no es más que una conceptualización de una actuación de la administración dirigida a ordenar una conducta a un particular sobre la base del incumplimiento de una norma. En tal sentido, no existe — salvo por el momento de su imposición (lo cual puede tener consecuencias en su régimen de imposición) - mayor diferencia conceptual entre las medias preventivas y correctivas. Las medidas cautelares, por el contrario, sí tienen la particularidad de encontrarse sujetas a la existencia de un pronunciamiento posterior que las legitime y les otorgue fijeza.

\section{III.1. Jurisprudencia y decisiones administrativas en materia de medidas correctivas}

El primer caso a reseñar es la sentencia del Tribunal Constitucional (TC) recaída en el expediente 1963-2006-PA/TC. En este proceso de amparo se cuestionó la capacidad del INDECOPI de ordenar medidas correctivas de forma adicional a la una sanción impuesta por infracciones a las normas de libre competencia. El TC señaló en el considerando 20 de la sentencia que «admitir que el Indecopi no puede ordenar el cese de conductas, sería negarle capacidad real para actuar dentro de sus facultades, las cuales fueron otorgadas para hacer prevalecer los fines constitucionales de protección a la libre competencia [...]» (las cursivas son nuestras). A criterio del TC, esa negación implicaría, además, admitir el absurdo de que los infractores pueden mantener conductas ilegales si cumplen con la sanción impuesta.

La relevancia de este caso radica en que el TC reconoce que la posibilidad de emitir medidas de policía es un necesario complemento de la potestad sancionadora. No admitirlo sería «negarle capacidad real para 
actuar dentro de sus facultades», lo cual apoya la idea de la potestad de dictar medidas de policía como implícita a la función administrativa.

Sobre los límites a dicha potestad, en un caso de infracción de las normas de competencia desleal, la comisión de represión de la competencia desleal señaló mediante la resolución 035-2007/CC, emitida en el expediente 109-2006/CCD, que denegaba la solicitud del denunciante de que se ordene el cierre del local del infractor aduciendo que «debe considerarse que las medidas correctivas a dictarse dentro de un procedimiento sancionador, como el presente, deben responder siempre a criterios de razonabilidad, proporcionalidad, y adecuación. En ese sentido, para que una medida correctiva sea reputada válida, además de razonable y proporcional, esta tiene que tener una correspondencia entre el fin que busca lograr y la materialización misma de la medida [...]».

Un importante ejemplo de imposición de medida correctiva, sin la necesidad de la existencia de una infracción, es un caso resuelto por el consejo directivo de SUNASS mediante su resolución 063-2006-SUNASS-CD. La gerencia general de SUNASS impuso como medida correctiva que la empresa procediera a devolver a los usuarios afectados los montos cobrados por concepto de «inspección interna» dentro de los procedimientos de reclamos comerciales más intereses. La empresa apeló dicha decisión ante el consejo directivo argumentando que no cometió infracción alguna, a pesar de lo cual se le impuso una medida correctiva, la cual viene a ser un complemento de la sanción. En tanto no existe infracción, no existe situación que restablecer. Finalmente, la empresa indicó que no existía norma que prohíba el cobro de un servicio colateral no regulado. $\mathrm{Al}$ resolver el recurso, el consejo directivo determinó que a pesar de no existir infracción, esto no implica que:

[...] la SUNASS se encuentre impedida de imponer a EMAPICA S.A una medida correctiva cuando la Gerencia de Supervisión y Fiscalización de la SUNASS verifique el incumplimiento de obligaciones por parte de dicha EPS [...]. En el presente caso la EPS ha efectuado cobros no autorizados por inspección interna dentro de un procedimiento de reclamos comerciales, habiendo infringido el artículo $58^{\circ}$ del Reglamento de la Ley General de Servicios de Saneamiento [...] el cual establece que las EPS no podrán efectuar cobro alguno por conceptos por los que no se encuentren expresamente autorizadas [...] no debe interpretarse que las medidas correctivas solo pueden imponerse siempre que acompañen como complementos a las sanciones administrativas, es decir que deban tener una sanción previa como condición para su existencia [...] En este sentido, la aplicación de medidas correctivas es totalmente independiente de cualquier procedimiento administrativo sancionador o de cualquier sanción que se imponga dentro de dichos procedimientos, bastando para su imposición, que se verifique el incumplimiento 
de obligaciones [...] si existe una situación que restablecer, la cual se materializa en la gratuidad de la prueba de inspección interna que se realice dentro del procedimiento de reclamos, es decir la eliminación del cobro indebido [...].

Finalmente, la exposición de motivos de la resolución de consejo directivo 029-2008-CD/OSIPTEL (Proyecto de Reglamento de Fiscalización, Infracciones y Sanciones del OSIPTEL) señala que:

[...] incluir una definición de medidas correctivas, comprendiendo en ella a toda actuación del OSIPTEL cuya finalidad sea revertir los efectos que hubiere producido una conducta infractora o el incumplimiento de alguna disposición - legal, contractual o técnica - que no configure en estricto una infracción administrativa (pero a cuyo cumplimiento se encuentra sujeta la empresa operadora) [...] Se trata, por tanto, de mecanismos mediante los cuales, los órganos competentes para imponer sanciones, se encuentran facultados para ordenar a las empresas operadoras la realización de una determinada conducta o la abstención de la misma, con la finalidad que estas den cumplimiento a sus obligaciones, legales, contractuales o técnicas sin que de su naturaleza se desprenda que se trata de sanciones administrativas, por carecer del contenido aflictivo o punitivo propio de la sanción. [...] De acuerdo a lo indicado, dada su naturaleza distinta a la de las sanciones administrativas, su utilización puede ser complementaria o excepcionalmente alternativa a esta última. Con relación a la posibilidad de ordenar medidas correctivas con carácter alternativo a la sanción, debe precisarse que la norma es clara en señalar que esta, únicamente será factible, en aquellos casos en los que el incumplimiento detectado no hubiere causado daños o habiéndolos causado, sus efectos resultaran susceptibles de ser eliminados, a través del pleno y total restablecimiento de la situación alterada al estado anterior a la comisión de la conducta [...] (las cursivas son nuestras).

Se incurre en un error al considerar que la sanción puede ser alternativa a una sanción en caso de infracción. A nuestro parecer, esta forma de utilizar la medida correctiva puede ser fácilmente remplazada por una correcta graduación de la sanción. El frecuente uso del OSIPTEL de tipificación indirecta de forma incorrecta ha provocado una sobredimensión de la conductas sancionables, ante lo cual se quiere utilizar a las medidas correctivas alternativas a las sanciones como forma de atenuar los efectos extremadamente gravosos que una sanción grave o muy grave puede tener en las empresas operadoras ante incumplimientos menores que, sin embargo, se encuentran «tipificados» en vía indirecta.

Como se puede observar, en el Perú existe un uso bastante heterogéneo de las medidas correctivas. En general, lo más común es encontrarlas de forma complementaria a una sanción, también es común encontrarlas tipificadas como sanción de forma errónea. Además, es común encontrar disposiciones que habilitan a dictar medidas correctivas listadas 
taxativamente en una norma. Consideramos que todo ello demuestra el desconocimiento de las medidas correctivas como medidas de policía administrativa y los supuestos habilitantes para su utilización, a pesar de lo cual existen pronunciamientos — como los reseñados previamenteque demuestran un entendimiento y uso correcto de la institución.

\section{CONCLUSIONES Y RECOMENDACIONES}

Debemos tener presente que el objetivo de una política regulatoria no es la imposición de sanciones de forma indiscriminada, sino, prevenir que se perturbe el ordenamiento jurídico al desincentivar las conductas contrarias al mismo. La fiscalización no debe tener siempre como fin imponer una sanción. Es necesario que se privilegie la utilización de instrumentos que permitan alertar y corregir antes que buscar expandir el área de influencia del Derecho administrativo sancionador hacia incumplimientos poco relevantes. Un organismo regulador no debe convertirse en un inquisidor irracional. Durante los últimos años, la imposición de sanciones ha aumentado considerablemente, pero no queda claro si ello ha tenido un efecto significativo en los distintos mercados. Debe analizarse qué tipo de conductas merecen ser calificadas como una infracción y solamente acudir al Derecho administrativo sancionador si el daño provocado al administrado mediante su imposición realmente genera una inflexión en el comportamiento de los agentes; es decir, si genera un efecto real en el mercado. La práctica internacional lleva a pensar que las sanciones - para que, en efecto, tengan un efecto desincentivadordeben ser por las conductas calificadas como más graves.

Poner en práctica un sistema de soft-enforcement a través del uso de medidas de policía en un país como el Perú resulta bastante complejo, pues implica que las instituciones tengan una legitimidad que permita que el ciudadano confíe en el criterio que en ellas se maneja al analizar cuándo es necesario sancionar y cuándo resulta suficiente recurrir a otro tipo de incentivos que parten del diseño de estrategias interiores del organismo regulador, así como del diseño de una política regulatoria adecuada. Las medidas correctivas — como cualquier otra institución jurídica- son herramientas para el logro de un determinado objetivo. En el caso del servicio público, el objetivo es garantizar su prestación bajo parámetros predeterminados.

No debemos expandir de forma innecesaria la acción de la potestad sancionadora, pues existen otros instrumentos igualmente satisfactorios para el régimen del servicio público. La tipificación indirecta y las leyes sancionadoras en blanco han sido utilizadas frecuentemente, pero no debemos dirigirnos hacia una atenuación del principio de tipificación, sino hacia la utilización de otras herramientas. La potestad de dictar medidas de policía administrativa es una condición necesaria para el ejercicio de la función administrativa. Asimismo, su uso permite no generar 
una hipertrofia de la potestad sancionadora, a la par que se mantiene la atención en el interés público.

Si bien las medidas de policía administrativa son un instrumento legítimo con el que cuenta la administración, no es menos cierto que su ejercicio debe estar reglado. En primer lugar, deben establecerse supuestos claros para su imposición, comenzando por el diseño de un procedimiento administrativo que responda a las características de este tipo de medida. En segundo lugar, deben determinarse los principios a los cuales debe sujetarse la imposición de este tipo de medida, como los ya mencionados principios de proporcionalidad y razonabilidad y el respeto al derecho de defensa del administrado. Ello, por ejemplo, debe servir para determinar las actuaciones concretas que debe seguir la administración para la imposición de una medida correctiva, los plazos a los que debe sujetarse, las formas de acreditar el cumplimiento de las misma, etcétera.

Por otro lado, un aspecto importante es que la obligación cuyo cumplimiento se exige a través de una medida correctiva debe razonablemente surgir de la norma que en teoría la establece; algo contrario puede llevar a arbitrariedades por parte de la administración. Si bien no han sido materia de análisis específico en el presente ensayo, las medidas correctivas ordenadas en el marco de los procedimientos administrativos por infracción a las normas de protección al consumidor y de defensa de la libre y leal competencia son cuestionadas por la relativa indeterminación y desconocimiento del alcance de las medidas correctivas que pueden ser ordenadas. Consideramos que el origen de dicho cuestionamiento es que las medidas correctivas en tales procedimientos se sustentan en la infracción de normas que no prescriben un comportamiento específico, sino en normas que pueden ser interpretadas de forma bastante amplia como, por ejemplo, la definición de un producto o servicio no idóneo. Si bien ello puede servir para reprimir conductas reprochables a través de la imposición de multas, al momento de ordenar conductas específicas por parte del administrado puede derivar en arbitrariedades o excesos, pudiendo incluso llegarse a que se confundan con medidas indemnizatorias. El cuestionamiento de actuaciones excesivas por parte de la administración debe estar comprendido en el diseño de un procedimiento de imposición de medidas correctivas en el que habilite el uso de medios impugnatorios pertinentes.

Al respecto, la resolución 103-2010 del consejo directivo del Osiptel (Proyecto de Reglamento de Fiscalización, Infracciones y Sanciones), publicada recientemente, refleja una evolución en la concepción de las medidas correctivas, pues en sus artículos 26 a 29 diseña un modelo de procedimiento para la imposición de dichas medidas, lo que puede servir como punto de partida para el futuro desarrollo y entendimiento de la institución. 